\title{
PENINGKATAN KEMANDIRIAN MERAWAT DIRI ANAK RETARDASI MENTAL DENGAN TERAPI OKUPASI DI SDLB NEGERI LAMONGAN
}

\section{Improvement of Self-Care Independence for Children with Mental Retardation Using Occupational Therapy in SDLB Negeri Lamongan}

\author{
${ }^{1}$ Abdul Rokhman, ${ }^{2}$ Fatkhur Rohmah \\ 1. Universitas Muhammadiyah Lamongan \\ 2. Universitas Muhammadiyah Lamongan \\ e-mail: ns.abdulrokhman@gmail.com
}

\begin{abstract}
ABSTRAK
Anak dengan retardasi mental mengalami ketergantungan pada orang tua dalam melakukan aktivitas sehari-hari seperti dalam hal kemandirian merawat diri sehingga bentuk latihan atau terapi yang dapat diberikan yaitu dengan terapi okupasi. Tujuan penelitian ini adalah untuk mengetahui pengaruh terapi okupasi terhadap tingkat kemandirian merawat diri pada anak retardasi mental di SDLB Negeri Lamongan.

Desain penelitian menggunakan desain eksperimental yaitu quasi eksperimental dengan pendekatan one group pre-post test design. Populasi dalam penelitian ini adalah seluruh siswa SDLB Negeri Lamongan sebanyak 28 anak. Pengambilan sampel menggunakan pusposive sampling sehingga didapatkan jumlah sampel sebanyak 15 anak. Pengumpulan data dilakukan dengan menggunakan lembar observasi kemandirian. Observasi dilakukan selama 3 minggu dengan 5 kali pertemuan, tiap pertemuan selama $\leq 1$ jam di SDLB Negeri Lamongan.

Hasil uji statistik wilcoxon sign rank test pada penelitian ini didapatkan hasil $p$ value $=0,001$ dimana $p<0,05$ dengan nilai $Z-3,411$ dan pada $Z_{\text {tabel }}$ adalah 1-0,0032 karena uji 2 sisi, hasil $Z_{\text {hitung }}$ menjauhi angka kritis $Z \pm 1,96$ dengan menjauhi kearah kiri yang berarti Ho ditolak yang berarti ada pengaruh terapi okupasi terhadap tingkat kemandirian merawat diri pada anak retardasi mental di SDLB Lamongan. Hasil penelitian menunjukkan tingkat kemandirian merawat diri sebelum diberikan terapi okupasi sebagian besar dalam ketergantungan sedang dan sesudah diberikan terapi okupasi sebagian besar dalam kategori mandiri.

Terapi okupasi dapat menumbuhkan dan meningkatkan kemandirian, terutama kemampuan fungsi aktivitas sehari- hari, khususnya dalam hal merawat diri (Nasir \& Muhith, 2011).
\end{abstract}

Kata Kunci : Terapi Okupasi, Kemandirian Merawat Diri, Retardasi Mental

\begin{abstract}
Children with mental retardation depend on parents in carrying out daily activities such as in terms of self-care independence so that exercise or therapy that can be applied is occupational therapy. The purpose of this study is to determine the effect of occupational therapy on the level of self-care independence in children with mental retardation at SDLB Negeri Lamongan.

The design of this study is experimental design that is quasi experimental with one group pre and post test design. The population in this study were all students of SDLB Lamongan were 28 children. Sampling used a purposive sampling so that the number of samples was 15 children. Data collection was carried out using independence observation sheet. Observations were performed for 3 weeks with 5 meetings, each meeting for $\leq 1$ hour in SDLB Negeri Lamongan.

The results of the Wilcoxon sign rank test in this study showed that $p$ value $=0.001$ where $p$ $<0.05$ with $Z-3.411$ and $Z$ table is 1-0.0032 due to 2-sided test, the result of $Z$ count is far from the critical number $Z \pm 1,96$ by moving to the left, which means that Ho is rejected, which means there is influence of occupational therapy on the level of self-care independence in children with mental retardation at SDLB Negeri Lamongan. The results of this study showed that the degree of independence of self-care before being given occupational therapy was mostly in moderate dependence category and after being given occupational therapy mostly in independent category.

Occupational therapy can produce and increase independence, especially the ability in daily activities in terms of caring for themselves (Nasir \& Muhith, 2011).
\end{abstract}

Keywords: Occupational Therapy, Independence of Self-Care, Mental Retardation 


\section{PENDAHULUAN}

Setiap anak diharapkan tumbuh dan berkembang secara optimal baik fisik, mental, maupun sosial sesuai dengan bertambahnya usia. Tercapainya tumbuh kembang yang optimal tersebut tergantung pada potensi biologiknya, yang merupakan hasil interaksi berbagai faktor yang saling berkaitan yaitu faktor genetik, lingkungan, bio-psiko-sosial dan perilaku .

Istilah anak berkelainan mental dalam beberapa referensi disebut dengan retardasi mental. Menurut World Health Organization (WHO 1990), retardasi mental adalah kemampuan mental yang tidak mencukupi. Sedangkan definisi yang dikemukakan oleh Diagnostic and Statistical Manual of Mental Disorders IV (DSM, 1994), retardasi mental merupakan gangguan yang ditandai oleh fungsi intelektual yang berfungsi secara bermakna dibawah rata-rata (Intelligence Quotient (IQ) kira-kira 70 atau lebih rendah) yang bermula sebelum usia 18 tahun disertai defisit atau hendaya fungsi adaptif.

WHO memperkirakan jumlah anak dengan disabilitas adalah sekitar $7-10 \%$ dari total populasi anak. Amerika 3\% dari penduduknya mengalami keterbelakangan mental, sedangkan di negara Belanda sekitar 2,6\% dan di Asia penyandang retardasi mental sekitar $\pm 3 \%$. Di Indonesia, menurut data Badan Pusat Statistik Nasional tahun 2007, terdapat 8,3 juta jiwa anak dengan disabilitas dari total populasi anak di Indonesia (82.840.600 jiwa anak), atau sekitar 10\%. Berdasarkan Pendataan Program Perlindungan Sosial (PPLS) tahun 2011, retardasi mental 30.460 anak dan mantan penderita gangguan jiwa 2.257 anak (Kemenkes, 2014).

Anak dengan retardasi mental cenderung tergantung pada orang lain, yang dapat dilihat dalam aktivitas sehari-harinya seperti kegiatan makan dan minum yang masih memerlukan bantuan dari orang lain, sehingga anak sulit untuk memenuhi kebutuhan makan dan minumnya sendiri khususnya dalam hal merawat diri sehingga mereka perlu diajarkan/dilatih secara khusus dalam bentuk bimbingan dan latihan (Rahmawati et al., 2012, Somantri, 2012).

Faktor yang mempengaruhi kemampuan anak retardasi mental dalam melakukan perawatan diri berasal dari faktor internal dan faktor eksternal. Faktor internal diantaranya berasal dari faktor usia dimana usia pada anak retardasi mental tidak dapat disamakan dengan usia perkembangan anak normal. Usia pada anak retardasi mental lebih ditekankan pada perkembangan mentalnya yang setara dengan 8 bulan per tahun kalender (Semiun, 2010). Selain itu juga faktor internal bisa juga berasal dari kemampuan kognitif, kondisi fisik, pertumbuhan, dan perkembangan sehingga perkembangan anak retardasi mental sangat terlambat dibandingkan anak normal. Terutama dalam perkembangan motorik, bahasa, sosial dan kognitif (Sandra, 2010). Sedangkan faktor eksternal diantaranya berasal dari faktor lingkungan dan keluarga.

Keterbatasan yang diakibatkan dari kondisi ketunaan/kecacatan pada diri masing-masing anak berkebutuhan khusus, berakibat pada hambatan perkembangan untuk menguasai ilmu pengetahuan, ketrampilan serta kemandirian seperti layaknya anak normal pada umumnya. masalah ini berakibat pada perkembangan proses kemandirian dalam hidupnya, apabila mereka tidak menguasai ketrampilan dan kemandirian bina diri, sehingga mereka memerlukan pendidikan program khusus yang bertujuan untuk meningkatkan kemempuan mereka dalam kemandirian untuk aktivitas hidup sehari-hari baik di sekolah, di rumah maupun di lingkungan masyarakat (Fadilah, 2008)

Penanganan umum pada anak retardasi mental adalah masalah pendidikan, edukasi, dan latihan. Bentuk latihan atau terapi yang sering diajarkan untuk anak retardasi mental antara lain seperti terapi perilaku, terapi bermain, dan terapi okupasi. Terapi yang paling cocok digunakan dalam mengatasi masalah dalam merawat diri dari ketiga terapi tersebut adalah dengan terapi okupasi. Terapi okupasi adalah perpaduan antara seni dan ilmu pengetahuan untuk mengarahkan penderita kepada aktivitas selektif agar kesehatan dapat ditingkatkan dan dipertahankan, serta mencegah kecatatan melalui kegiatan atau kesibukan kerja untuk penderita cacat mental maupun fisik (Nasir and Muhith, 2011).

Berdasarkan latar belakang tersebut maka peneliti tertarik untuk melakukan penelitian pada anak retardasi mental untuk mengetahui 
"Pengaruh Terapi Okupasi Terhadap Tingkat Kemandirian Merawat Diri pada Anak Retardasi Mental di SDLB Negeri Lamongan”.

\section{METODE}

Penelitian ini termasuk jenis penelitian yang menggunakan desain penelitian eksperimental, dengan pendekatan Quasi Eksperimental dengan One Group Pre-Post Test Design. Populasi dalam penelitian ini adalah seluruh siswa SDLB Negeri Lamongan sebanyak 28 siswa. Pengambilan sampel menggunakan pusposive sampling sehingga didapatkan jumlah sampel sebanyak 15 siswa yang sesuai dengan kriteria inklusi diantaranya anak yang mengikuti terapi sampai selesai dan anak RM dengan IQ 36-51.

Instrumen penelitian ini menggunakan lembar observasi kemampuan perawatan diri dan skala tingkat kemandirian berdasarkan Courtesy of the Rehabilitation Institute Of Chicago. Siswa SDLB di observasi tingkat kemandiriannya sebelum dilakukan terapi, kemudian diberikan terapi okupasi perawatan diri yang meliputi menggosok gigi, menyisir rambut, dan memakai baju. Terapi dilakukan sebanyak 5 kali pertemuan. Setelah pertemuan kelima siswa di observasi tingkat kemandiriannya, dan selanjutnya dianalisis menggunakan uji Wilcoxon.

\section{HASIL DAN PEMBAHASAN HASIL}

1. Data Umum

a. Umur Anak

Tabel 1 Karakteristik Responden Berdasarkan Umur Anak Retardasi Mental di Sekolah Dasar Luar Biasa (SDLB) Negeri Lamongan

\begin{tabular}{clcc}
\hline No. & \multicolumn{1}{c}{ Umur } & Frekuensi & $(\boldsymbol{\%})$ \\
\hline 1 & $>$ 12 Tahun & 6 & 40 \\
2 & $9-12$ Tahun & 7 & 47 \\
3 & 6-8 Tahun & 2 & 13 \\
& Total & 15 & 100 \\
\hline
\end{tabular}

Sumber: Data primer 2018

Berdasarkan tabel 1 di atas menunjukkan bahwa sebagian besar umur responden adalah 9-12 tahun yaitu sebanyak 7 orang (47\%), sedangkan sebagian kecil umur responden adalah 6-8 tahun yaitu sebanyak 2 orang (13\%). b. Jenis Kelamin Anak
Tabel 2 Karakteristik Responden Berdasarkan Jenis Kelamin Anak Retardasi Mental di Sekolah Dasar Luar Biasa (SDLB) Negeri Lamongan

\begin{tabular}{clcc}
\hline No. & $\begin{array}{c}\text { Jenis } \\
\text { Kelamin }\end{array}$ & Frekuensi & $(\boldsymbol{\%})$ \\
\hline 1 & Laki-laki & 10 & 67 \\
2 & Perempuan & 5 & 33 \\
& Total & 15 & 100 \\
\hline
\end{tabular}

Sumber: Data primer 2018

Dari tabel 2 di atas menunjukkan bahwa sebagian besar jenis kelamin anak adalah lakilaki yaitu sebanyak 10 orang (67\%).

c. Tingkat Retardasi Mental Anak

Tabel 3 Karakteristik Responden Berdasarkan Tingkat Anak Retardasi Mental di Sekolah Dasar Luar Biasa (SDLB) Negeri Lamongan

\begin{tabular}{clcc}
\hline No. & Kelompok & Frekuensi & $\mathbf{( \% )}$ \\
\hline 1 & Ringan & 5 & 33 \\
2 & Sedang & 10 & 67 \\
3 & Berat & 0 & 0 \\
& Total & 15 & 100 \\
\hline
\end{tabular}

Sumber: Data primer 2018

Dari tabel 3 di atas menunjukkan bahwa sebagian besar tingkat retardasi mental anak adalah sedang yaitu sebanyak 10 orang (67\%), sedangkan untuk tingkat ringan sebanyak 5 orang (33\%).

2. Data Khusus

a. Tingkat kemandirian merawat diri sebelum diberikan terapi okupasi

Tabel 4 Distribusi Frekuensi Tingkat Kemandirian Merawat Diri Sebelum Diberikan Terapi Okupasi di Sekolah Dasar Luar Biasa (SDLB) Negeri Lamongan

\begin{tabular}{clcc}
\hline No. & $\begin{array}{c}\text { Tingkat } \\
\text { Kemandirian } \\
\text { Merawat Diri }\end{array}$ & Frekuensi & (\%) \\
\hline 1 & Penuh & 0 & 0 \\
2 & Berat & 2 & 13 \\
3 & Sedang & 9 & 60 \\
4 & Ringan & 4 & 27 \\
5 & Mandiri & 0 & 0 \\
& Total & 15 & 100 \\
\hline
\end{tabular}

Sumber: Data primer 2018

Berdasarkan tabel 4 di atas menunjukkan bahwa sebagian besar anak retardasi mental mengalami ketergantungan sedang dalam kemandirian merawat diri sebelum dilakukan 
terapi okupasi yaitu sebanyak 9 orang (60\%), sedangkan sebagian kecil anak retardasi mengalami ketergantungan berat yaitu sebanyak 2 orang (13\%)

b. Tingkat kemandirian merawat diri sesudah diberikan terapi okupasi

Tabel 5 Distribusi Frekuensi Tingkat Kemandirian Merawat Diri Sesudah Diberikan Terapi Okupasi di Sekolah Dasar Luar Biasa (SDLB) Negeri Lamongan

\begin{tabular}{clcc}
\hline No. & $\begin{array}{l}\text { Perkembangan } \\
\text { Motorik Halus }\end{array}$ & Frekuensi & $\begin{array}{c}\text { Prosentase } \\
(\boldsymbol{\%})\end{array}$ \\
\hline 1 & Penuh & 0 & 0 \\
2 & Berat & 0 & 0 \\
3 & Sedang & 3 & 20 \\
4 & Ringan & 6 & 40 \\
5 & Mandiri & 6 & 40 \\
& Total & 15 & 100 \\
\hline
\end{tabular}

Sumber: Data primer 2018

Berdasarkan tabel 5 di atas menunjukkan bahwa sebagian besar anak retardasi mental mengalami mandiri dan ketergantungan ringan dalam kemandirian merawat diri sesudah dilakukan terapi okupasi yaitu sebanyak 6 orang (40\%), sedangkan sebagian kecil anak retardasi mengalami ketergantungan sedang yaitu sebanyak 2 orang $(20 \%)$.

c. Pengaruh Terapi Okupasi Terhadap Tingkat Kemandirian Merawat Diri Pada Anak Retardasi Mental

Tabel 6 Tabel Silang Pengaruh Terapi Okupasi Terhadap Tingkat Kemandirian Merawat Diri Pada Anak Retardasi Mental di Sekolah Dasar Luar Biasa (SDLB) Negeri Lamongan

\begin{tabular}{lccccc}
\hline Terapi & \multicolumn{4}{c}{ Tingkat Kemandirian Merawat Diri } \\
\cline { 2 - 6 } Okupasi & Penuh & Berat & Sedang & Ringan & Mandiri \\
\hline Pre & $0 \%$ & $13 \%$ & $60 \%$ & $27 \%$ & $0 \%$ \\
Post & $0 \%$ & $0 \%$ & $20 \%$ & $40 \%$ & $40 \%$ \\
\hline
\end{tabular}

Sumber: Data primer 2018

Berdasarkan tabel 6 di atas menunjukkan bahwa sebelum dilakukan terapi okupasi tingkat kemandirian merawat diri pada anak retardasi mental sebagian besar mengalami ketergantungan sedang sebanyak $60 \%$, sedangkan untuk ketergantungan ringan $27 \%$ dan ketergantungan berat $13 \%$. Setelah diberikan terapi okupasi tingkat kemandirian merawat diri pada anak retardasi mental mengalami peningkatan dari ketergantungan sedang menjadi ringan sebanyak $40 \%$

d. Hasil Analisa Pengaruh Terapi Okupasi Terhadap Tingkat Kemandirian Merawat Diri Pada Anak Retardasi Mental

Tabel 7 Hasil Analisa Pengaruh Terapi Okupasi Terhadap Tingkat Kemandirian Merawat Diri Pada Anak Retardasi Mental di Sekolah Dasar Luar Biasa (SDLB) Negeri Lamongan

\begin{tabular}{lcccc}
\hline & N & $\begin{array}{c}\text { Median } \\
\text { (Minimum- } \\
\text { Maksimum) }\end{array}$ & P & Z \\
\hline Pre & 15 & $52(26-64)$ & 0,001 & $-3,411$ \\
Post & 15 & $62(42-74)$ & & \\
\hline
\end{tabular}

Sumber: Data primer 2018

Berdasarkan tabel 7 hasil pengujian dengan di uji Wilcoxon dengan SPSS hasil didapatkan nilai Z -3,411 (tanda negatif (-) tidak relevan, karena hanya menunjukkan arah). Ini berarti probabilitas adalah 1-0,0032 karena uji 2 sisi, maka probabilitas (asymp. sig) adalah 0,001. Hasil $\mathrm{Z}_{\text {hitung }}$ menjauhi angka kritis $\mathrm{Z} \pm 1,96$ dengan menjauhi ke arah kiri sehingga Ho ditolak artinya ada pengaruh terapi okupasi terhadap tingkat kemandirian merawat diri pada anak retardasi mental.

\section{PEMBAHASAN}

\section{Karakteristik Pada Anak Retardasi Mental}

Berdasarkan tabel 1 dapat dijelaskan bahwa sebagian besar umur responden adalah 9-12 tahun yaitu sebanyak 7 orang (47\%), sedangkan sebagian kecil umur responden adalah 6-8 tahun yaitu sebanyak 2 orang (13\%). Pada anak retardasi mental yang berusia 9-12 tahun, mereka sudah dapat melakukan kegiatan seharihari walaupun masih dibantu dan bergantung pada orang tuanya. Berdasarkan tabel 2 di atas menunjukkan bahwa sebagian besar jenis kelamin anak adalah laki-laki yaitu sebanyak 10 orang (67\%), sedangkan untuk anak perempuan sebanyak 5 orang (33\%). Pada penelitian ini jenis kelamin laki-laki lebih banyak dibandingkan perempuan. Sandra (2010) menyatakan bahwa anak retardasi mental lebih banyak berjenis kelamin laki-laki 
dibandingkan wanita. Menurut Kaplan \& Saddock (2010), bahwa retardasi mental 1,5 kali lebih beresiko terjadi pada laki-laki dibandingkan perempuan. Hal ini disebabkan oleh mutasi gen yang terjadi pada kromosom $\mathrm{X}$.

Berdasarkan tabel 3 di atas menunjukkan bahwa sebagian besar tingkat retardasi mental anak adalah sedang yaitu sebanyak 10 orang (67\%), sedangkan untuk tingkat ringan sebanyak 5 orang (33\%). Pada anak retardasi mental ringan mereka memiliki IQ 52-69 yang artinya mereka masih mampu untuk dididik. Kategori retardasi mental sedang memiliki IQ 36-51 yang artinya mereka masih mampu dilatih untuk memiliki kemampuan perawatan diri, sedangkan pada anak retardasi mental berat dan sangat berat mengalami kesulitan dalam merawat diri. Anak tunagrahita sedang disebut juga imbesil. Kelompok ini memiliki IQ 51-36 pada Skala Binet dan 54-40 menurut Skala Weschler (WISC).

\section{Tingkat Kemandirian Sebelum Diberikan Terapi Okupasi}

Berdasarkan tabel 4 di atas menunjukkan bahwa sebagian besar anak retardasi mental mengalami ketergantungan sedang dalam kemandirian merawat diri sebelum dilakukan terapi okupasi yaitu sebanyak 9 orang (60\%), sedangkan sebagian kecil anak retardasi mengalami ketergantungan berat yaitu sebanyak 2 orang (13\%).

Hasil penelitian ini didukung oleh penelitian terdahulu oleh Sari (2012), yang menyebutkan kemandirian anak retardasi mental mengalami masalah sehingga perlu diberikan suatu terapi dan latihan. Pada kebutuhan perawatan diri sebagian (partially compensatory system), membutuhkan bantuan perawat dalam pengkajian pemenuhan kebutuhan perawatan diri klien, menyediakan kebutuhan perawatan diri akibat keterbatasan klien dan membantu klien sesuai yang dibutuhkan (Nursalam, 2011)

Dalam penelitian tersebut disebutkan bahwa sebagian besar anak retardasi mental mengalami ketergantungan sedang dalam melakukan kegiatan sehari - hari sebelum diberikan tindakan dan terapi tertentu.

\section{Tingkat Kemandirian Sesudah Diberikan Terapi Okupasi}

Berdasarkan tabel 5 di atas menunjukkan bahwa hampir sebagian anak retardasi mental mengalami mandiri dan ketergantungan ringan dalam kemandirian merawat diri sesudah dilakukan terapi okupasi yaitu sebanyak 6 orang (40\%), sedangkan sebagian kecil anak retardasi mengalami ketergantungan sedang yaitu sebanyak 2 orang (20\%). Pada anak retardasi mental yang mengalami tingkat sedang dan ringan telah menunjukkan berbagai perkembangan dan peningkatan dalam hal kemandirian merawat diri. Sesudah diberikan terapi okupasi anak retardasi mental mampu untuk dilatih dan bisa melakukan dalam kehidupan sehari-harinya secara mandiri walaupun tidak semua yang menjadi responden menjadi mandiri.

Anak retardasi mental dapat dimandirikan dengan memberikan pengetahuan dan keterampilan tentang kegiatan kehidupan sehari-hari agar mereka dapat merawat diri sendiri khususnya kemandirian dalam perawatan diri tanpa tergantung pada bantuan orang lain. Salah satu terapi yang bisa diberikan kepada anak retardasi mental untuk dapat meningkatkan kemandiriannya adalah terapi okupasi (Nasir \& Muhith, 2011).

Tujuan terapi okupasi ini dapat untuk mengembalikan fungsi fisik, meningkatkan aktivitas gerak sendi, kekuatan otot dan koordinasi gerakan, mengajarkan aktivitas kehidupan sehari-hari seperti makan, berpakaian, belajar menggunakan fasilitas umum baik dengan atau tanpa alat bantu, serta mengajarkan anak mandi dengan bersih, dan juga melatih anak untuk melakukan pekerjaan rutin di rumah dan memberikan saran penyederhanan ruangan maupun letak alat-alat kebutuhan sehari-hari (Nasir \& Muhith, 2011).

\section{Pengaruh Terapi Okupasi Terhadap Tingkat Kemandirian Merawat Diri Pada Anak Retardasi Mental}

Hasil penelitian ini menunjukkan bahwa tingkat kemandirian merawat diri pada anak retardasi mental sesudah diberikan terapi okupasi mengalami peningkatan dari sebelum diberikan terapi okupasi. Sesuai dengan hasil analisis uji Wilcoxon hasil didapatkan nilai $\mathrm{Z}$ 3,411 dengan tingkat signifikan $0,001(\mathrm{p}<0,05)$. 
$H_{0}$ ditolak artinya ada pengaruh terapi okupasi terhadap tingkat kemandirian merawat diri pada anak retardasi mental.

Berdasarkan tabel 6 di atas menunjukkan bahwa sebelum dilakukan terapi okupasi tingkat kemandirian merawat diri pada anak retardasi mental sebagian besar mengalami ketergantungan sedang sebanyak $60 \%$, sedangkan untuk ketergantungan ringan $27 \%$ dan ketergantungan berat $13 \%$. Setelah diberikan terapi okupasi tingkat kemandirian merawat diri pada anak retardasi mental mengalami peningkatan dari ketergantungan sedang menjadi ringan sebanyak $40 \%$ dan untuk ketergantungan ringan menjadi mandiri sebanyak $40 \%$.

Menurut Nurlina (2008) menyebutkan bahwa terapi okupasi dapat membantu anak retardasi mental agar dapat mengaktualisasikan potensinya sebagaimana mestinya.

Hasil penelitian ini juga didukung penelitian oleh Permatasari (2013) yang menyatakan bahwa ada pengaruh terapi okupasi melalui kegiatan sulam pita untuk meningkatkan motorik halus anak retardasi mental sedang siswa SMPLB kelas VII di SLB ABCD Tunas Pembangunan I Rembun Nogosari Boyolali. Terapi yang diberikan yaitu dengan memberikan contoh cara merawat diri yang benar misalnya menggosok gigi, mandi, memakai baju dan berhias. Peneliti memberikan contoh cara menggosok gigi, mandi, memakai baju dan berhias yang benar kemudian anak retardasi mental disuruh untuk menirukan.

Hasil penelitian ini juga sejalan dengan penelitian yang dilakukan oleh Emck, et al (2009), yang menyatakan bahwa anak dengan gangguan mental, kognitif (intelektualitas) dan perilaku seringkali menunjukkan kemampuan motorik kasar yang rendah dan tidak mampu dalam menilai kemampuan motoriknya sendiri. Kemampuan motorik yang rendah pada anak dengan retardasi mental akan berpengaruh pada kemampuan perawatan diri, yang artinya apabila kemampuan motorik anak rendah, maka kemampuan perawatan dirinya akan lebih rendah jika dibandingkan dengan anak yang kemampuan motoriknya baik (Raffi, Indriati, \& Utami, 2018).

\section{KESIMPULAN}

Berdasarakan hasil penelitian dan pembahasan maka dapat disimpulkan bahwa :

1. Lebih dari sebagian $(60 \%)$ anak retardasi mental di SDLB Negeri Lamongan sebelum dilakukan terapi okupai mempunyai tingkat kemandirian merawat diri sedang.

2. Hampir sebagian (40\%) anak retardasi mental di SDLB Negeri Lamongan sesudah dilakukan terapi okupai mempunyai tingkat kemandirian merawat diri mandiri.

3. Terdapat Pengaruh Terapi Okupasi Terhadap Tingkat Kemandirian Merawat Diri Pada Anak Retardasi Mental di Sekolah Dasar Luar Biasa (SDLB) Negeri Lamongan.

\section{DAFTAR PUSTAKA}

EMCK, et al. 2009. Gross motor performance and self-perceived motor competence in children with emotional, behavioral, and pervasive developmental disorder: a review. Developmental Medicine \& child neurology. USA: Thesis

FADILAH, L. 2008. Kendala penerapan terapi ABA (Applied Behavior Analysis) terhadap kemandirian anak retardasi mental /GDD di Pusat Terapi Terpadu A Plus Malang. Master, Universitas Islam Negeri Malang.

KAPLAN \& SADOCK 2010. Sinopsis Psikiatri: Ilmu pengetahuan perilaku psikiatri klinis jilid 2, Jakarta, Bina Rupa Aksara.

KEMENKES 2014. Situasi penyandang disabilitas. Buletin Jendela: Data dan informasi kesehatan. Jakarta: Kemenkes RI.

NASIR, A. \& MUHITH, A. 2011. Dasar-dasar keperawatan jiwa: pengantar dan teori, Jakarta, Salemba Medika.

NURLINA 2008. Terapi okupasi untuk keterampilan pita rambut pada anak tunagrahita. Jurnal Pendidikan Luar Biasa, 4.

NURSALAM 2011. Manajemen keperawatan: Aplikasi dalam praktik keperawatan profesional, Jakarta, Salemba Medika. 
PERMATASARI, N. 2013. Pengaruh terapi okupasi melalui kegiatan sulam pita untuk meningkatkan motorik halus bagi anak tunagrahita sedang siswa SMPLB kelas VII di SLB ABCD Tunas Pembangunan I Rembun Nogosari Boyolali. Magister, Universitas Sebelas Maret.

RAFFI, I., INDRIATI, G., \& UTAMI, S. 2018. Efektifitas pemberian terapi okupasi dalam meningkatkan kemandirian makan pada anak usia sekolah dengan down syndrome. Jurnal Keperawatan Sriwijaya, Vol.5 (1), 1-11.

RAHMAWATI, D., ALLENIDEKANIA \& BESRAL 2012. Kemampuan perawatan diri anak tuna grahita berdasarkan faktor eksternal dan internal anak. Jurnal Keperawatan Indonesia, 15, 89-96.
SANDRA, M. 2010. Metode pembelajaran dan terapi untuk anak berkebutuhan khusus, Yogyakarta, Katahati.

SARI, N. 2012. Hubungan komunikasi asertif orang tua dengan kemandirian anak retardasi mental. Jurnal Keperawatan STIKES Wira Medika PPNI Bali, 5, 1218.

SEMIUN, Y. 2010. Kesehatan mental 2, Yogyakarta, Kanisius.

SOETJININGSIH 2012. Tumbuh kembang anak, Jakarta, EGC.

SOMANTRI, S. 2012. Psikologi anak luar biasa, Bandung, Refita Aditama.

WHO 1990. The work of WHO : Biennial report the director-general. 